\title{
Risk assessment in the maintenance operations of health equipments
}

\author{
Fernanda Rodrigues ${ }^{\mathrm{a}}$, Nuno Teixeira ${ }^{\mathrm{b}}$ \\ a Department of Civil Engineering, Geobiotec, University of Aveiro. Campus Universitário de Santiago, 3810- \\ 193 Aveiro, Portugal \\ b Institute of Welding and Quality - Portugal,nuno.teixeira@fmc-ag.com
}

\begin{abstract}
The Human activity is always associated with a probability of risk exposure that have to be eliminated or kept in an acceptable level. The acceptable level concept depends on the self evaluation in function of different subjective and objective factors, being extremely important to quantify objectively the risk. The risk assessment permits to get the knowledge of the working interactions that have to be studied and determine what kind of interventions must be implemented, when and how. The maintenance activities of medical equipments such as for hemodialysis and peritoneal dialyses, involve diverse occupational risk. During this study its assessment was carried out through the SOBANE methodology - Screening Observation Analysis Expertise (in the Screening phase). The risk assessment depicts that the principal hazards those technicians are exposed are related with ergonomics, psychosocial, electrical, fall at the same level, biologics and fire. The aim of this paper is to present the results of the risk assessment during maintenance activities of hemodialysis and peritoneal dialyses equipments.
\end{abstract}

Keywords: Equipments maintenance, hemodialysis, peritoneal dialysis, hazards, case study

\section{Introduction}

The Human activity is always associated with a probability of risk exposure that have to be eliminated or kept in an acceptable level. The acceptable level concept depends on the self evaluation in function of different subjective and objective factors, being extremely important to quantify objectively the risk. The risk assessment permits to get the knowledge of the working interactions that have to be studied, and determine what kind of interventions must be implemented, when and how. The principal aims of this assessment are $[1,2]$ :

- Identify the exposed workers;

- Identify the most adequate preventive and protective measures;

- $\quad$ Establish the interventions hierarchy;
- $\quad$ Establish the actions program;

- $\quad$ Organize the necessary resources.

The working conditions, the type of processes, the technical complexity and the particular risks of the activities are the factors that conditioned the selection of the assessment method. These methods are normally based on the [3-6]:

- $\quad$ Surrounding observation of the workplace;

- Identification of the activities developed in the workplace;

- Observation of the activities in progress;

- Consideration of the external factors that can affect the workplace.

The maintenance activities of medical equipments involve diverse occupational risk. Its assessment was

\footnotetext{
*Corresponding author E-mail: mfrodrigues@ua.pt 
carried out through the SOBANE methodology Screening Observation Analysis Expertise (in the Screening phase) [7].

The SOBANE methodology is based on two determinants factors of its success when applied in the case study: the participation of the team managers in the treatment of "sensitive themes", and the different qualifications of the workers. The workers' participation in the risk assessment in this methodology makes them more conscious of the hazards and risks of their work activities.

The risk assessment of the maintenance technicians of hemodialysis and peritoneal dialyses equipments depicts that the principal hazards they are exposed are related with ergonomics, psychosocial, electrical, fall at the same level, biologics and fire.

The aim of this paper is to present the assessment risk methodology applied during the risk assessment of maintenance activities of medical instruments of kidney insufficiency treatment and the correspondents' results.

\section{Risk assessment}

Patients who lost their kidney function and irreparably reached the terminal stage of renal disease have nowadays three methods of treatment which replace the functions of the kidney: peritoneal dialysis, hemodialysis and renal transplantation.

Dialysis is an artificial process that serves to remove by filtration, all undesirable substances accumulated by renal chronicle disease. This can be done using the filter membrane of the artificial kidney and/or the peritoneal membrane.

The equipments used in these treatments are maintained in the internal installations of the maintenance enterprise or in the treatments site (customers). This paper describes the occupational risk assessment of the maintenance technicians of the hemodialysis and peritoneal dialyses equipments in those two situations of work.

\subsection{SOBANE strategy}

The European and Portuguese legislation requires the employer to ensure workers safety and health in all aspects related to work, according to the implementation of the general prevention principles [8]. The SOBANE strategy seeks to apply the general principles of prevention in a more operative and effective way [7]:
- $\quad$ Preventive priority: give priority to preventing risks and improving the physical and social aspects of work and not to the personal protection equipment and health monitoring;

- Risk factors: a risk factor corresponds to an aspect of the work situation which can lead to negative consequences for safety, health and welfare of the worker. The risk will depend on the degree of exposure and on the risk conditions under which the exposure occurs. Therefore, the probability of occurrence of an effect with certain gravity "G", taking into account exposure "E", the risk conditions "C" under which the exposure occurs and the qualification and motivation "M" for safety and health of the employee who is exposed to the risk factor, lead to: Risk $=\mathrm{M}^{*} \mathrm{G}^{*} \mathrm{E}^{*} \mathrm{C}$.

- Risk prevention: the risk reduction can be achieved by acting consistently in "E" in the organization of work (reducing sources of risk, ...), in " $C$ " adopting the collective safety protections, in " $G$ " adopting the personal safety equipment and in " $M$ " by the training and motivation of workers.

The SOBANE risk management strategy consists of four progressive levels of implementation [7]: Sreening, Observation, Analyze, and Expertise. The Sreening phase is implemented regardless of the nature of the need to improve the work situation (complaints, accidents, ...). Problems are addressed in its own context and other aspects that also affect the safety, health and welfare are also identified. The solutions are sought in the context of the global situation of work. The next levels (Observation, Analyze, Expertise) are only started if the previous level could not solved completely the problem. The need to engage a level above depends on the complexity of the problems encountered in the work situation. The measures implemented in the first two phases have not relevant cost associated. The upper stages are more expensive, but have higher added value, since they are used with a targeted and appropriate way. Thus, the SOBANE strategy leads a real improvement in the work situation, faster and with lower costs. The SOBANE strategy also makes clearer the action of the various groups involved in the risk management: people of the working situation conduct independently the Observation and Secreening phases, while the safety services are indispensable in the Analysis phase and the experts in the Expertise phase. 


\subsection{Secreening phase}

The aim of this phase is to identify safety problems and correct simple and obvious errors or faults. A small group of workers and their supervisors and a element of the safety service reviews the main aspects in the work situation, seeking improvement actions for immediate implementation and the needs for further study.

It is designated an employee to coordinate this phase and to ensure the implementation of immediate actions and continuing the study of items to be examined in greater detail (phase 2. Observation).

\section{Case study}

\subsection{Working sites}

Technical assistance in the equipment assistance company is carried out in a single floor space designated Repair Shop.

The Repair Shop consists on three distinct areas for the repair of equipments for hemodialysis (HD), for peritoneal dialysis (PD) and for hemodialysis for acute patients. There is a common area to all equipment and accessories disinfection, a reception area for equipments and other products that come from customers and also an area for the repaired and new equipments.

The technical assistance process in the Repair Shop can be defined in the following steps:

1. Disinfection of equipment and supplies received (except if there is written information indicating that they are disinfected);

2. Carrying out the tasks of technical assistance;

3. Disinfection of the used tools;

4. Disinfection of the repaired equipment.

When the service is performed at the customer site, usually there is a defined area to carry out the activities, but sometimes they are done in the local where the equipment is used by the patients.

The technicians spend approximately three hours driving to arrive to the clients carrying in the vehicle the stock of pieces, tools, test equipment and laptop.

The process of technical assistance on the client can be defined in the following steps:

1. Moving to the customer;

2. Disinfection of the equipment surface;

3. Disinfection of the hydraulic circuits (in case of intervention in the hydraulic systems);

4. Carrying out the tasks of technical assistance;
5. Disinfection of the used tools and supplies;

6. Disinfection of the replaced accessories.

\subsection{Results analysis}

For the assessment was selected two technicians that work on the costumers' site (external technician) and one that works on the Repair Shop (internal technician). The questionnaires were adapted to the characteristics of the activity of each group. It is underlined that the activity of the external technicians on the customer sites has risks associated with the facilities so, require a particular approach with the adoption of workers defensive behaviors and the proposal of facilities improvement.

\subsubsection{Internal technician assessment}

From the analysis of the technical questionnaire the area that stands out with higher risk associated with corresponds to the chapter of "occupational hygiene", in which the biological hazard highlight. It was considered that training on safety procedures related to biohazards will minimize this risk. The decision of the realization of the training is under "aspects to consider in more detail", and should be reviewed by the higher levels of decision.

About the remaining chapters of the questionnaire, another significant item for the minimisation of biohazards is the importance of disinfecting tools after completion of a job, as described in the internal safety statement. Other hazards to take into consideration, but with less emphasis, are related with "places and areas of work", "occupational accidents" and "electrical and fire ".

Under "places and areas of work", it is considered that when there are peaks of high amount of equipment on the sites, it must be prepared in a more organized and safer way. It was considered for study/decision at a upper level of decision measures of work organisation, namely the technical equipment assistance planning SleepSafe and infrastructure adaptations, such as plant floor leveling and work flow optimising.

Under "occupational accidents" it was identified for study/decision at a upper level of decision the acquisition of a transportation car for the movement of SleepSafe equipments and training on safety procedures in emergency situations, e.g. evacuation in case of fire. In the chapter of "electrical and fire" it was identified for study/decision improvements in the electrical installation including the installation of 
additional electrical power sockets in the area of technical assistance of the SleepSafe equipment and the identification of one of the electrical control panel. The replacement of an emergency fire button and the fire hydrant repair should also be considered. In the remaining chapters of the questionnaire it is considered that the risks are acceptable.

\subsubsection{External technician assessment}

From the corresponding questionnaire it was stand out as greater risks those ones associated with "working positions" mainly due to the reduced area intended for the implementation of the work, found on some clients sites, and the "occupational hygiene" in which the chemical and biological hazards are relevant. Regarding the "ocupational hygiene", external technicians considered that the washing of the working clothes in the company and the regular training on safety procedures related to biological and chemical hazards, will contribute to the better control of these risks. It was also mentioned that the access to the internal safety procedures and data sheets of chemicals could be more effective with trainee on internal software for documentation distribution. The decision for the implementation of these measures is in the context of "aspects to consider in more detail", and should be reviewed by the higher levels of decision.

Other risks to be taken into consideration, but with less emphasis than the thematic of working positions and occupational hygiene, are the chapters of "places and work areas", "technical organization of jobs", "occupational accidents", "efforts and handling of loads", "lighting", " work contents ", "schedule pressure" and "psychosocial environment".

Under the "places and work areas" it was considered for study/decision of higher decision levels, proposals for the technical improvement of the maintenance places in the clients' sites.

Under the heading of "technical organization of jobs" it is important that external technicians use a box for placing contaminated pieces. For the study/decision of the upper decision levels was proposed: work organisation measures which enable better planning with alternation of maintenance with repair work to make it less monotonous; use of a centralized stock for all external technicians in order to decrease the individual stock; the use of a single trolley to transport tools and equipment.

\section{Conclusions}

The SOBANE methodology is not frequently used in Portugal and it was chosen due to its basic principles, indicating better success in the final objective which is the maintenance and prevention of safety and health of workers.

During this work the SOBANE methodology was based on two factors that definitely have conditioned their success: the opening of managers for the approach of "sensitive issues" and the differentiated skills of the workers. As expected, the component of the employees' participation in risk assessment strengthened the hazards and risks awareness of the functions or work situations under study.

This methodology solves more effectively the "obvious risks" and additional studies, usually expensive, are only addressed after all the "obvious measures" are implemented.

\section{References}

[1] C Europeia, Guia para avaliação de riscos no local de trabalho, Bruxelas: Serviço de publicações Comunidades Europeias, 1997 (in Portuguese).

[2] M. Glossop, A. Loannides, J. Gould, Review of hazard identification techniques (RAS/00/02): HSL, 2000.

[3] M. Hernández, E. Fernández, G. Muñoz, A. Prada, Evaluatión de riesgo laborales. Madrid: Instituto Nacional de Seguridad e Higiene en el Trabajo, 1996.

[4] G. Lluna, Sistema de Gestión de Riesgos Laborales e Industriales, Editorial MAPFRE S.A., Madrid, 1997.

[5] J. MacDonald, D. Hnopman, J. R. Lockwood, H. Willis, Unexploded ordnance: A Critical review of risk assessment methods: RAND Corporation, 2004.

[6] W. M. Keyserling, A. B. Bigelow, M. L. Brower, L. A. Murphy, Ergonomic job analysis: Methods to identify, evaluate, and control exposures to risk factors in the workplace. In B. Das (Ed.), Advances in Industrial Ergonomics and safety II: Taylor \& Francis, 1990.

[7] J. Malchaire et al., Strategie SOBANE et guide de depistage deparis, Belgium, 2006.

[8] M. Roxo, Segurança e Saúde do Trabalho: Avaliação e Controlo de Riscos. Livraria Almedina, 2003. 